\title{
A LEITURA DO MUNDO ATRAVÉS DA TECNOLOGIA EDUCACIONAL: A ADOÇÃO DA ROBÓTICA PEDAGÓGICA NAS PRÁTICAS DE DEMOCRATIZAÇÃO DO CONHECIMENTO CIENTÍFICO
}

\section{THE READING OF THE WORLD THROUGH EDUCATIONAL TECHNOLOGY: THE ADOPTION OF PEDAGOGICAL ROBOTICS IN THE PRACTICES OF DEMOCRATIZATION OF SCIENTIFIC KNOWLEDGE}

\author{
Heitor Felipe da Silva \\ Universidade Federal de Pernambuco \\ heitor_felipe@hotmail.com
}

Ana Beatriz Gomes Pimenta de Carvalho

Universidade Federal de Pernambuco

anabeatrizgpc@gmail.com

RESUMO: Este artigo apresenta um Mapeamento Sistemático da Literatura (MSL) acerca da democratização do conhecimento científico e das práticas de alfabetização e letramento científico com adoção da robótica pedagógica em tais práticas, a fim de consolidar resultados publicados em veículos dedicados à divulgação do conhecimento científico. O mapeamento sistemático da literatura foi realizado em 2018, considerando trabalhos entre os anos de 2010 a 2017. Como base de dados, inicialmente foram escolhidos o Catálogo de Teses e Dissertações da CAPES e a Biblioteca Digital Brasileira de Teses e Dissertações, e posteriormente o Google Scholar. A partir da combinação de buscas foram recuperados quatro artigos, dos quais três foram considerados relevantes para extração e análise de dados via software EndNote. O mapeamento pode mostrar o quão pouco são realizados trabalhos voltados ao uso da robótica pedagógica como ferramenta de auxílio às práticas de democratização do conhecimento científico.

PALAVRAS-CHAVE: robótica pedagógica; letramento científico; democratização; conhecimento; ciência e tecnologia.

ABSTRACT: This article presents a Systematic Literature Mapping (MSL, in Portuguese) about the democratization of scientific knowledge and the practices of literacy and scientific literacy with the adoption of pedagogical robotics in such practices, in order to consolidate results published in vehicles dedicated to the dissemination of scientific knowledge. The systematic mapping of the literature was carried out in 2018, considering works between the years 2010 to 2017. As a database, the Catalog of Theses and Dissertations of CAPES and the Brazilian Digital Library of Theses and Dissertations were initially chosen, and later Google Scholar. From the combination of searches, four articles were retrieved, of which three were considered relevant for extraction and data analysis through EndNote software. The mapping can show how little work is done on the use of pedagogical robotics as a tool to help the practices of democratization of scientific knowledge.

KEYWORDS: pedagogical robotics; scientific literacy; democratization; knowledge; science and technology. 


\section{Alfabetização científica e letramento científico}

Estudos construtivistas da psicogênese da língua escrita mostram que para apropriar-se dos processos de leitura e escrita, o sujeito cria hipóteses que interferem na maneira como tais processos são utilizados (FERREIRO; TEBEROSKY, 1991). Esquemas análogos presentes na apropriação da língua escrita foram estudados no campo da Educação Científica ${ }^{1}$, que teve momentos marcados por estudos de natureza construtivista. Ao longo do tempo, a visão atribuída à alfabetização como apropriação da tecnologia de codificar e decodificar palavras foi sobrepujado, abrindo espaço para as práticas de letramento: "Inspirados na epistemologia, muitos educadores e pesquisadores propuseram que a Educação em Ciências passasse a ser compreendida como um processo de mudança conceitual" (PAULA; LIMA, 2007, p. 5).

O indivíduo se apresenta alfabetizado através do domínio e utilização do conhecimento sobre o uso das técnicas ligadas à utilização do código fonético para realizar o intercâmbio entre o transcrever fonemas em palavras e o oralizar palavras escritas. De forma análoga, pensemos sobre os sujeitos que recebem uma "alfabetização científica". Podemos falar sobre aqueles que adquirem algum tipo de conhecimento sobre ideias, fórmulas e acontecimentos sobre ciências no sistema de ensino do qual fazem parte. Esses conhecimentos científicos (vamos nos referir às Ciências Naturais) podem ser úteis para ajudar um estudante a obter uma boa nota em um exame da sua escola ou vestibular. Esse estudante pode saber utilizar as fórmulas referentes às Leis de Newton, diferenciar uma bactéria de vírus e fungos etc., sem que tenha se apropriado dos aspectos da cultura científica (PAULA; LIMA, 2007).

Através dos conhecimentos científicos, o indivíduo pode passar por uma transformação positiva a partir do momento em que ele consegue fazer a leitura do mundo, conhecer e compreender as suas necessidades. Para Chassot $(2000,2003)$, a ciência é um instrumento cultural capaz de interpretar o mundo natural mediante o entendimento de fatos já ocorridos e previsões sobre eventos futuros.

Ao considerar a ciência como a linguagem facilitadora à leitura e compreensão do mundo, podemos aceder aos princípios de Freire (1969) no que se refere à alfabetização do indivíduo dentro do seu contexto social, quebrando o paradigma do processo de alfabetização feito sob a memorização de conceitos, datas, equações e outros assuntos em uma participação passiva. Freire conseguiu transformar o processo de alfabetização de adultos em um processo dinâmico de leitura do próprio mundo. "Aqui, reforça-se que é fundamental transformar a educação científica num processo que possibilite aos alunos a leitura do mundo e a interpretação/reflexão sobre os acontecimentos presentes em nossa dura realidade" (RUI, 2012, p. 68).

Para Chassot (2003), fazer ciência - assim como a aquisição de todos os conhecimentos elaborados sob a metodologia científica - está relacionada a explicação do mundo natural. Porém, o pesquisador chama a atenção para que não se faça uma interpretação reducionista da ciência ou ao que se refere como mundo natural ${ }^{2}$.

1 "De sua parte, o ensino da Ciência - compreendendo os preceitos da Ciência, Matemática e Tecnologia - deve ajudar os alunos a desenvolverem os conhecimentos e hábitos da mente imprescindíveis para a formação de cidadãos capazes de pensar criticamente e enfrentar os desafios da vida" (ACADEMIA BRASILEIRA DE CIÊNCIAS. Disponível em: <http://www.abc.org.br/>. Acesso em: 19 abr. 2018).

2 Para Chassot (2003), o mundo natural, devido às restrições epistemológicas, fica limitado ao mundo 
Defendo, como depois amplio, que a ciência seja uma linguagem; assim, ser alfabetizado cientificamente é saber ler a linguagem em que está escrita a natureza. É um analfabeto científico aquele incapaz de uma leitura do universo (CHASSOT, 2003, p. 91).

Para fazer os estudantes compreenderem melhor o universo através do entendimento da ciência, Chassot (2003) acredita que há diversas possibilidades para realizar esse trabalho sem descartar a questão relativa às correções feitas nos ensinamentos que são apresentados de forma distorcida.

Durante as décadas de 1980 e 1990, o Brasil vivenciou uma fase na qual o ensino era centrado na necessidade de os estudantes adquirir conhecimento científico através da transmissão massiva de conteúdo. Entre os índices de eficiência do docente, se destacava aquele medido pela quantidade de páginas repassadas aos estudantes. Estes, por sua vez, eram considerados familiarizados aos assuntos quando os "sabiam de cor" tinham decoradas as teorias, fórmulas, leis e conceitos dos processos científicos (CHASSOT, 2003).

Seguindo as considerações trazidas por Chassot, relembramos as concepções denunciadas por Freire (1969) no que ele denominou como uma Educação Bancária. Os professores eram considerados os sujeitos da ação educacional (depositários) e os alunos os seus repositórios de conhecimento.

Hoje não se pode mais conceber propostas para um ensino de ciências sem incluir nos currículos componentes que estejam orientados na busca de aspectos sociais e pessoais dos estudantes. Dessa forma, encontramos no Letramento Científico uma proposta que visa a uma educação voltada ao desenvolvimento de competências e habilidades que tornam o estudante capaz de realizar uma leitura crítica e inferir no ambiente em que ele vive.

Teixeira (2007) nos apresentou que o Letramento Científico (LC) possui uma relação intrínseca com o ensino-aprendizagem e a aquisição das habilidades inseridas no ensino formal de ciências, e complementa que

Também está ligado com o que o aluno precisa saber sobre ciência para fazer uma leitura crítica do mundo em que vive e como ele interage com este mundo, além de enxergar e analisar criticamente como a sociedade em que ele vive interage, interpreta e transforma o ambiente que o cerca (TEIXEIRA, 2007, p. 23).

Destarte, quando o sujeito em questão não faz uso dos conhecimentos científicos construídos para alargar os seus horizontes para a interpretação e compreensão de fenômenos de natureza científica (naturais, sociais, etc.), ou aplicar conhecimentos previamente divulgados que possam sanar problemas cotidianos enfrentados na sociedade, estamos face a um sujeito alfabetizado, porém não letrado cientificamente.

Apesar das diferenças entre as propostas teóricas, a alfabetização pode ser definida como o nível mínimo de habilidades de leitura e escrita que uma pessoa deve ter para participar da comunicação escrita (SABBATINI, 2004). Além disso, é preciso

visível o qual fazemos parte. Porém ele ressalta que as outras ciências que tratam de questões de cunho emocional, político e social também fazem parte do mundo natural, ficando apenas de fora as consideradas ciências (ou manifestações) sobrenaturais. 
perceber que qualquer que seja a definição dada à alfabetização, ela será profundamente pertencente às características da sociedade que a utiliza, devido à diversidade de sistemas sociais e econômicos existentes no mundo.

Ainda no seu trabalho, Sabbatini (2004) defende que a alfabetização científica se propõe a demonstrar o nível de cientificidade da cultura de uma sociedade, ou seja, é exibir em qual medida as instituições científicas, seus conteúdos, práticas, processos e discursos se encontram refletidos na sociedade. O conceito de cultura científica como traço individual se revela insuficiente para compreender a circulação e uso social do conhecimento, assim como a participação cidadã. Em adição, destaca que, uma vez que a ciência e a tecnologia são assumidas como parte da sociedade, se faz necessário um maior nível de integração desses conceitos para converter a intitulada cultura científica em conteúdos notórios nas práticas gerais e presentes no sentido comum.

Existe uma preocupação na Legislação Brasileira a respeito do preparo do aluno para o seu exercício cidadão, através da aproximação da educação escolar às práticas sociais que envolvam a aplicação do conhecimento científico construído.

No documento Matriz de Avaliação de Ciências, do PISA 2015, o Letramento Científico é definido como "a capacidade de se envolver com as questões relacionadas com a ciência e com a ideia da ciência, como um cidadão reflexivo" (INEP, 2015, p. 7). Nos estudos de Pereira e Teixeira (2015), é apontado o papel que a escola deve assumir para que o aluno tenha acesso ao conhecimento científico e assim consiga desenvolver o senso crítico indispensável a uma melhor compreensão do mundo, através da oferta de um ambiente propício à descoberta, investigação científica e elaboração de conceitos sobre fenômenos de ordem natural, social, tecnológica etc.

É preciso destacar que não há um consenso ou definição única sobre os termos Alfabetização Científica e Letramento Científico. Entretanto, é compreendido que a alfabetização científica se relaciona ao domínio da nomenclatura científica e compreensão de termos e conceitos científicos, enquanto o letramento científico leva em consideração competências e habilidades necessárias para a utilização dessas informações, mas não necessariamente levando em consideração a questão social do indivíduo.

Nessa concepção, é de grande importância destacar os ensinamentos de Paulo Freire (1990) quando ele alerta que não se deve desagregar o "ler a palavra" de "ler o mundo", pois tornar-se um indivíduo alfabetizado vai além de identificar os símbolos do alfabeto e reconhecer as palavras. Uma vez que o ato de alfabetizar faz a pessoa pensar de uma forma diferente da sua de costume, ele cria uma diferente percepção de mundo e assim leva à reflexão de que há diferentes tipos de alfabetizações.

As condições de não letrados cientificamente, no que diz respeito às Ciências Naturais, de acordo com Paula e Lima (2007), não estão restritas aos indivíduos que não tiveram uma base sólida de conhecimento científico na sua alfabetização científica, mas que podem ser vistas entre sujeitos considerados intelectuais. Estes indivíduos podem ser críticos e atuarem nos seus domínios de atividade profissional e cidadã. Entretanto, podemos encontrar cientistas voltados às Ciências Naturais que apresentam uma postura pouco crítica e até alienada sobre atividades pouco distantes de suas especialidades.

Uma discussão trazida por Paula e Lima (2007) traz uma reflexão sobre a definição dada por outros autores sobre Alfabetização Científica e Letramento Científico. De acordo com os autores, a definição apresentada por Krasilchik e Marandino (2004) traz a ideia de 
que a Alfabetização Científica abrange a concepção de Letramento Científico e dá oportunidade ao indivíduo para expressar suas opiniões acerca de ciência e tecnologia, participando da cultura científica quando este achar mais oportuno.

A oposição feita por Paula e Lima (2007) encontra-se no fato de a negação à diferenciação dos termos alfabetização e letramento, trazida por outros estudiosos ainda no campo da linguística, como Soares (1998), não foi levada em consideração por Krasilchik e Marandino (2004). Esses autores expressam de forma muito vaga como os estudantes teriam ampliado a sua capacidade de expressar opiniões sobre ciência e tecnologia e gozar de uma liberdade individual através da sua participação na cultura científica. Um dos destaques trazidos nessa crítica está no fato de alguns autores falarem sobre inclusão social, liberdade, poder cidadão, mas não fazem referência a que tipo de liberdade se deseja alcançar e nem o tipo de sociedade ou cidadania das quais falam em seus trabalhos.

$\mathrm{Na}$ nossa compreensão, o LC tem propósitos que ultrapassam a alfabetização científica. Ele faz uso do conhecimento científico para que o seu detentor possa se tornar um ser capaz de solucionar problemas práticos do seu dia a dia, assim como inferir nas tomadas de decisões acerca de atitudes que interfiram na sociedade. Para tanto, é preciso dar atenção especial às ações que envolvam o trabalho do vocabulário científico a fim de contribuir com a construção e aplicação do conhecimento científico.

\section{Vocabulário científico}

Em diferentes tipos de mídia é possível encontrar discussões ou informações acerca de temas diversos que envolvam ciência, tecnologia e sociedade. Esses conteúdos, por vezes, dissertam sobre meio ambiente, economia, avanços na medicina, desenvolvimento ou aprimoramento de novas tecnologias da informação e comunicação etc.

Para tanto, existem algumas fontes de informação especializadas nesses assuntos e que são dirigidas a públicos específicos. Podemos citar, como exemplo, portais para consultas de periódicos (como o Portal de Periódicos CAPES ${ }^{3}$, bastante divulgado na comunidade científica nacional); revistas como a Science, Galileu, Superinteressante; jornais como a Folha de São Paulo, O Globo; e podcasts como o Alô, Ciência?

Dependendo da fonte da informação e do público para o qual ela se direciona, a compreensão de alguns termos pode ser difícil devido à falta de familiaridade com o termo em si ou, em muitos casos, o público pode nunca ter se deparado com tais termos em outras situações.

3 O Portal de Periódicos, da Coordenação de Aperfeiçoamento de Pessoal de Nível Superior (Capes), é uma biblioteca virtual que reúne e disponibiliza a instituições de ensino e pesquisa no Brasil o melhor da produção científica internacional. Ele conta com um acervo de mais de 38 mil títulos com texto completo, 134 bases referenciais, 11 bases dedicadas exclusivamente a patentes, além de livros, enciclopédias e obras de referência, normas técnicas, estatísticas e conteúdo audiovisual. Fonte: <https://goo.gl/QAf8LU>. Acesso em: 12 dez. 2018.

4 Alô, Ciência? é um projeto voltado para a divulgação científica que busca discutir temas que sejam transversais ao mundo científico levando sempre em conta sua influência e importância em nossa sociedade. Fonte: <https://alociencia.com.br/sobre/>. Acesso em: 12 dez. 2018. 
Hoje em dia é possível encontrar publicações ou assistir a programas voltados à divulgação científica, que utilizam uma linguagem menos técnica. Porém alguns termos pertencentes a algumas áreas específicas não podem ser substituídos por sinônimos, cabendo ao redator (ou qualquer outro indivíduo responsável pela divulgação da informação) se fazer valer de recursos diversos para explicar tal termo (seja através do uso de notas de rodapé, hiperlinks, hipertextos etc). Quando ocorre esse fenômeno, acontece uma contribuição para a ampliação do vocabulário científico daqueles que se deparam com esse novo termo. Para Gomes (1995), trata-se do fenômeno da vulgarização lexical que está relacionada às ações de divulgar, propagar e difundir uma informação científica.

Em sua pesquisa, Gomes (1995) traz as Fases da Vulgarização que foram definidas por Poupet $^{5}$ (1994) e que se apresentam em cinco fases que vão desde a linguagem utilizada pelo cientista à divulgação da informação para o grande público. Essas fases estão divididas em:

1. linguagem do pesquisador: linguagem utilizada com muitos termos técnicos e neologismos, direcionada aos pesquisadores e técnicos. Geralmente, é utilizada nas revistas dedicadas a um público especializado;

2. linguagem heurística: linguagem docente utilizada em conceituações levadas ao público de nível universitário, apresentada por um especialista. Esta é uma linguagem voltada para a leitura, compreensão e redação;

3. linguagem dos usuários: nessa linguagem, os termos técnicos da língua de especialidade começam a ser substituídos por alguns termos da língua comum. Nesta fase é criada uma linguagem funcional e acessível para que o objetivo de "informar" possa ser alcançado;

4. vulgarização científica: nesta fase acontece a divulgação da informação científica voltada a um grande público (porém, não podemos chamar de "divulgação em massa", uma vez que ela não acontece em meios acessíveis a todos que possuem interesse). Normalmente, é encontrada em revistas e jornais científicos.

\begin{abstract}
A vulgarização para o grande público: neste momento, o público ao qual se destina a divulgação científica não é e não é pretendido fazer dele um grupo de especialistas. Este é o público que se informa através da TV, rádio, podcasts, canais do Youtube, etc. Esta fase engloba os artigos que são publicados em cadernos de grandes jornais e também em revistas em quadrinhos com o intuito de conscientizar, esclarecer ou apresentar novos assuntos às crianças e adolescentes (GOMES, 1995, p. 86).
\end{abstract}

Como exemplo dessa vulgarização científica, podemos verificar o trabalho de Judy Culkin (2011) intitulado Introduction to Arduino ("Introdução ao Arduino"), com quadrinhos criados para a introdução à robótica através do uso da plataforma Arduino ${ }^{6}$. Nesse

5 O esquema foi apresentado por Armelle Le Bars Poupet, durante o curso Métodos de Terminologia Comparada, acontecido na FFLCH-USP, em março de 1994.

6 O Arduino é um conjunto de ferramentas de prototipagem eletrônica open source que visa tornar mais fácil a criação de aparelhos eletrônicos. Além de oferecer uma placa controladora, ele possui também um ambiente de desenvolvimento, por isso é considerado uma plataforma e não simplesmente um hardware. Basta ligar a placa ao computador e já é possível escrever códigos para o Arduino no ambiente de desenvolvimento do software (através da linguagem $\mathrm{C} / \mathrm{C}++$ ). Fonte: 
trabalho, a professora desenvolveu um guia amigável e prático, em que utiliza de analogias com situações práticas e comuns para explicar alguns conceitos da Física. Em adição, Culkin disponibiliza o modelo desse material, junto a um guia, para que professores e outros profissionais ao redor do mundo possam traduzi-lo e/ou adaptar alguns termos para uma melhor compreensão pelo público que irá fazer a sua leitura. Através da sua iniciativa, esse trabalho é utilizado até hoje por alguns membros da Comunidade Arduino e o mesmo tem passado por algumas atualizações e traduções para que não se torne obsoleto.

Ao longo da análise feita sobre o trabalho de Culkin (2011), tomando como base a pesquisa de Gomes (1995), pôde-se notar que a vulgarização lexical na divulgação científica pode se dar de diversas maneiras. A exemplo, pode-se apontar as substituições de termos científicos por explicações utilizando expressões da linguagem comum (aqui nos referimos à linguagem não científica, que utiliza termos técnicos) e analogias para a explanação de alguns conceitos da Física.

Em complemento, é perceptível o interesse por parte dos autores (GOMES, 1995) à manutenção de um maior número de termos específicos às suas determinadas áreas de conhecimento, com o objetivo de aprimorar e enriquecer o vocabulário do público-alvo; possibilitando a compreensão de assuntos, mesmo que de maneira não muito aprofundada, que outrora eram apenas discutidos por especialistas. Dessa maneira, a vulgarização da linguagem científica torna-se mais um passo rumo à inclusão cidadã nos assuntos relacionados a C\&T e torna-se um instrumento facilitador para a construção do conhecimento científico.

Diante de toda a discussão acerca da divulgação do conhecimento científico, como o trabalho de Culkin (2011) para a comunidade Arduino, e as práticas de alfabetização e letramento voltadas às ciências, foi decidido realizar um mapeamento sistemático da literatura na busca da adoção da robótica pedagógica nas práticas de democratização do conhecimento científico.

\section{Mapeamento sistemático da literatura}

Um mapeamento sistemático da literatura é uma metodologia de pesquisa que objetiva identificar, avaliar e interpretar pesquisas relevantes a uma questão de pesquisa proposta (KITCHENHAM, 2004). Esta forma de estudo identifica lacunas onde novos estudos primários são necessários e agrupamentos de evidências que podem levar a novas revisões sistemáticas (SILVA et al., 2018).

Por se basear em um protocolo de pesquisa, esse mapeamento pode ser reproduzido por outros pesquisadores. Os itens que constituem tal protocolo são: objetivos de busca, palavras-chave, filtros, mecanismos de busca acadêmica (MBA), critérios de exclusão/inclusão e dados a serem levantados (OLIVEIRA; HOUNSELL; KEMCZINSKI, 2014).

Optou-se por realizar um mapeamento sistemático para que pudessem ser verificadas as pesquisas e outros levantamentos acerca do uso da Robótica Pedagógica (RP) no letramento científico para a democratização do conhecimento científico.

\footnotetext{
<https://www.opservices.com.br/o-que-e-o-arduino/>. Acesso em: 12 dez. 2018.
} 
$\mathrm{Na}$ definição do protocolo do mapeamento, foi feita a escolha por trabalhos na língua portuguesa, publicados entre os anos de 2010 e 2017. A string de busca foi definida como: "Construção de Conceitos CientíficoTecnológicos")AND(alfabetização)OR(Letramento)OR("Democratização do Conhecimento"), considerando o título dos trabalhos. Como base de dados, inicialmente foram escolhidos o Catálogo de Teses e Dissertações da CAPES e a Biblioteca Digital Brasileira de Teses e Dissertações.

Ao executar as buscas nas bases, nenhum trabalho foi encontrado utilizando a string criada. Sendo assim, optamos por realizar ajustes para fazer buscas mais amplas e com termos de grafias semelhantes. As strings e os seus resultados, para ambas as bases pesquisadas, foram os seguintes:

- ao utilizar uma busca utilizando lógica difusa, para considerar termos de grafias semelhantes, a string ficou ("Construção de Conceitos CientíficoTecnológicos")AND(robótica)OR(alfabetização)OR(Letramento)OR("Democratizaçã o do Conhecimento"). Como resultado, nenhum registro foi encontrado em ambas bases;

- ao remover as aspas para possibilitar uma busca mais ampla, a string criada foi (Construção de Conceitos Científico-Tecnológicos)AND(robótica)OR (alfabetização)OR(Letramento)OR(Democratização do Conhecimento). Como resultado, nenhum registro foi encontrado em ambas bases;

- quando utilizado um caractere coringa $\left(^{*}\right)$ para recuperar variações das palavras buscadas, a string de busca ficou da seguinte forma: ("Construção de Conceitos Científico-

Tecnológicos")AND(robótica)OR(alfabetização)OR(Letramento)OR(“Democratizaçã o do Conhecimento")*. Como resultado, nenhum registro foi encontrado em ambas bases.

Consideramos duas questões centrais para nortear o mapeamento realizado:

- Os trabalhos selecionados visam a propostas de trabalho relacionadas à alfabetização científica ou letramento científico através da RP?

- Quais as propostas e/ou métodos adotados para trabalhar assuntos de ciência e tecnologia na sala de aula?

As questões foram formuladas devido à necessidade de se buscar informações sobre as propostas de trabalhos que têm como propósito o desenvolvimento da cultura científica através da alfabetização e do letramento científico. Porém, apenas mapear essas propostas não era suficiente, pois a intenção também se encontra em descobrir os métodos adotados para se trabalhar assuntos ligados a ciência e tecnologia em ambiente escolar. A pesquisa foi realizada inicialmente nas bases de dados da Biblioteca Digital Brasileira de Teses e Dissertações pertencente ao Instituto Brasileiro de Informação em Ciência e Tecnologia (BDTD IBICT) e no Catálogo de Teses e Dissertações CAPES.

Uma vez que os resultados das buscas não estavam sendo satisfatórios, decidimos realizar uma última busca em uma outra base de dados, seguindo os mesmos critérios do protocolo definido. A base escolhida foi a Google Acadêmico ${ }^{7}$. Utilizando a string "Construção de Conceitos Científico-Tecnológicos")AND(robótica)OR 
(alfabetização)OR(Letramento)OR("Democratização do Conhecimento", encontramos quatro resultados que foram catalogados e analisados com o auxílio do software EndNote $X 7^{8}$, de acordo com um protocolo.

Para realizar a análise dos resultados encontrados na busca, definimos quatro critérios de inclusão $(\mathrm{Cl})$ e três critérios de exclusão (CE). O trabalho seria analisado se satisfizesse todos os Cls. Caso ele se enquadrasse em algum CE, era reprovado e não seguia para a análise. Essa seleção preliminar se deu através da análise dos resumos de cada trabalho encontrado. Aqui são apresentados os critérios de inclusão $(\mathrm{Cl})$ e critérios de exclusão (CE) criados:

- (CI1) Possuir algum dos termos pesquisados no seu título;

- (Cl2) Ser estudo realizado sobre trabalhos desenvolvidos com robótica educacional;

- (Cl3) Fazer parte do eixo Ciência e Tecnologia;

- (Cl4) Apresentar descrições de experiências que relatam trabalhos envolvendo alfabetização ou letramento científico através do uso da RE nas atividades escolares;

- (CE1) Não conter nenhum termo da string de busca no seu título;

- (CE2) Descrever a utilização da robótica pedagógica no ambiente escolar, mas não abordar o conhecimento de questões de C\&T, a produção de artefatos cognitivos e a democratização da informação;

- (CE3) O foco não corresponder à questão da pesquisa.

Os trabalhos foram identificados através do código de identificação "SCHOLAR_Número do trabalho" e exportados para a ferramenta EndNote X7. Posteriormente, foram armazenados e, então, tiveram os seus resumos lidos para que assim pudesse ser verificada a sua relevância e, em momento futuro, fizesse parte do grupo dos textos que seriam lidos por completo para integrar o processo de avaliação final.

A avaliação final é composta da leitura integral dos trabalhos selecionados na etapa da seleção preliminar, quando é realizada uma síntese geral contendo os resultados observados, assim como algumas outras considerações. Por meio dos critérios definidos no protocolo, todos os artigos encontrados na busca ${ }^{9}$ foram organizados no software EndNote X7 em um grupo nomeado "trabalhos encontrados", contendo quatro trabalhos. Mais três grupos foram criados, sendo um grupo chamado "trabalhos analisados", que recebeu quatro trabalhos que passaram por uma primeira triagem, na qual foi verificado se havia alguma duplicidade. Foi designado um outro grupo, chamado "trabalhos excluídos", para os textos analisados que não passaram pelos critérios de exclusão. Esse grupo recebeu um trabalho; e um último grupo, "trabalhos aceitos", foi criado para os artigos selecionados para a leitura e escrita desse mapeamento sistemático. Esse último

8 O EndNote Web é um gestor de referências bibliográficas online gratuito, que realiza pesquisas bibliográficas em diversas Bases de Dados de Informação Científico-Tecnológica (BDICT), tais como Web of Science e PubMed/Medline. Fonte: <http://www.seabd.bco.ufscar.br/bases-de-dados/basescapes/o-que-e-o-endnote-web>.

9 Um total de quatro trabalhos foi encontrado no recorte temporal definido. Uma nova busca foi realizada sem o recorte temporal de 2010 a 2017, porém os trabalhos relevantes também foram totalizados em quatro. 
grupo contém três trabalhos.

Da análise dos trabalhos pré-selecionados resultou um grupo chamado "trabalhos aceitos", contendo três obras com textos que apresentavam uma metodologia que aborda a produção de artefatos científicos e/ou tecnológicos através da RE, descrições de experiências que apresentavam trabalhos envolvendo alfabetização ou letramento científico através do uso da RE nas atividades realizadas. Foi percebido que o texto de ID Scholar_04 era igual ao Scholar_01, sendo o primeiro direcionado ao grupo "trabalhos excluídos".

O primeiro trabalho selecionado, Scholar_01, foi o de CÉSAR (2013), que é uma tese de doutorado na área de Difusão do Conhecimento, intitulada "Robótica pedagógica livre: uma alternativa metodológica para a emancipação sociodigital e a democratização do conhecimento". O trabalho foi desenvolvido na Universidade Federal da Bahia (UFBA) e tem como proposta a análise e discussão dos documentos criados a partir de sete oficinas sobre Robótica Pedagógica Livre (RPL) ministradas na UNEB (SALVADOR/BA) e na Universidad de la República/UY. Com o resultado dessa análise e discussão, é proposta uma metodologia de difusão do conhecimento sobre e para a RPL. As oficinas ministradas para os educandos consistiam de atividades para o desenvolvimento de kits de RPL e, no momento da multiplicação, esses educandos replicaram e difundiram atividades, que eles consideraram significativas, em outros espaços de aprendizagem. A investigação tem como foco a emancipação sociodigital e a democratização do conhecimento através do trabalho realizado com a RPL em Espaços Multirreferenciais de Aprendizagem (EMA). No tocante à (re)significação de conceitos por parte dos educandos, César (2013) aponta que a apropriação de elementos da RPL através das ações mediadas nas oficinas ministradas permitiram que as informações das experiências vivenciadas pelos educandos desencadearam descobertas de significações não só para si, como também para todo o grupo. Tal fato pode ser percebido no excerto que fala sobre a (re)criação de artefatos cognitivos pelos participantes das oficinas:

\footnotetext{
Nesse sentido, os educandos constroem artefatos, desenvolvidos nas oficinas de $\mathrm{RPL}$, cognoscíveis (para si, para os outros e para o mundo) a partir de sua projeção-imaginária na esfera do desejo-vontade e da reflexibilidade. Ou seja, a partir das experiências de aprendizagem nas oficinas de RPL, os atores se apropriam - utilizando os sentidos - de informações as atividades ministradas, e, de acordo com a linguagem, com as emoções e com a ética, eles (re)constroem os artefatos cognitivos (CÉSAR, 2013, p. 71).
}

Ao buscar informações sobre a emancipação sociodigital numa abordagem que se relaciona ao letramento científico, foi possível constatar que o trabalho de investigação, que resultou na tese em análise, destaca a importância do conhecimento gerado através do compartilhamento de informações e dos desafios propostos dentro do EMA da RPL, levando à possibilidade de geração de emprego e renda. Quanto ao papel dos educadores nesse processo emancipatório, o autor declara que:

Os educadores, através da educação, ciência e tecnologia, cultura, informações e conhecimento, propõem e discutem com os educandos alternativas de projetos/atividades que possam ser desenvolvidos no EMA da RPL e cujos desafios são a transformação social, a necessidade de uma sociedade de atores 
sociais livres, emancipados, desalienados e sustentadores de sua autonomia nas demais esferas da vida (CÉSAR, 2013, p. 72).

Através dos elementos apresentados, o trabalho analisado atende a todos os critérios de inclusão definidos no protocolo desse mapeamento sistemático.

O segundo trabalho analisado, Scholar_02, também de César (2009), é uma dissertação do mestrado do Programa de Pós-Graduação em Educação, UFBA, intitulado "Potencialidades e Limites da Robótica Pedagógica Livre no Processo de (Re)construção de Conceitos Científico-Tecnológicos a partir do Desenvolvimento de Artefatos Robóticos". Essa dissertação trata-se de uma pesquisa que objetiva analisar as potencialidades e limites da Robótica Pedagógica Livre no processo de (re)construção de conceitos científico-tecnológicos na formação de professores a partir do desenvolvimento de artefatos robóticos, na perspectiva da filosofia de softwares e hardwares livres.

Ao realizar a leitura dessa dissertação, chamou a atenção o fato da constante retomada às questões de inclusão digital, enfatizando a liberdade de produção e difusão do conhecimento científico e a emancipação do sujeito através de todo esse processo de produção seguindo as perspectivas do Software Livre dentro do contexto da RPL. Tal afirmativa pode ser conferida no excerto

A capacidade de acesso à tecnologia pode ser pré-condição para inclusão social e digital; ou seja, a capacidade de acesso de cada indivíduo às tecnologias contemporâneas (como os códigos-fonte dos softwares livres) depende das relações socioeconômico-culturais e cognitivas (CÉSAR, 2009, p. 29).

O trabalho também expõe a questão da (re)construção - como escrito pelo autor de conceitos científicos-tecnológicos e formação científica. Ele destaca que os cidadãos contemporâneos convivem, em seu cotidiano, com conceitos científico-tecnológicos, cujos significados, muitas vezes, não conhecem e são aplicações na realidade na qual vivem. Devido a essa razão, César (2009, p. 52) sinaliza a "importância do trabalho da (re)construção de conceitos científico-tecnológicos a partir do processo de formação científica dos educandos".

Algumas das indagações que ele traz em sua pesquisa são:

Será que as propostas pedagógicas de formação científica preparam os educandos para conviver com as mudanças tecnológicas? Elas os auxiliam no processo de (re)construção de conceitos científico-tecnológicos durante o processo de ensino e de aprendizagem? (CÉSAR, 2009, p. 53).

Através dessas indagações, o autor ressalta a importância da reflexão sobre a reprodução de antigas práticas e práxis pedagógicas tomadas por algumas escolas. Sendo assim, ele aponta a necessidade de uma

[...] formação continuada para os educandos durante o seu processo de formação científica, para auxiliar no entendimento da relação dialógica entre os processos de mudanças tecnológicas e o mundo a sua volta - transformações que podem alterar a sua forma de ver e pensar os problemas do mundo moderno (CÉSAR, 2009, p. 53). 
Ao realizar as oficinas de RPL, foi percebido que muitos participantes não tinham familiaridade com o computador e apresentavam dificuldades na identificação dos seus componentes, manuseio e trabalhos com o software computacional, porém possuíam contas de e-mail. Nesse momento foi identificada a Inclusão Digital como uma necessidade a ser trabalhada, pois ficou claro que "ter acesso aos computadores não é o bastante se não sabemos como utilizá-los adequadamente (CÉSAR, 2009, p. 69)".

As oficinas trabalharam a produção de uma Interface Hardware Livre (IHL), utilizando os princípios da RPL. Entre os temas propostos foi escolhido pelos educandos aprender o funcionamento de um pisca-pisca de árvore de Natal e criá-lo.

Ao longo dos encontros, foi percebido que os educandos passaram a entender e aplicar os conceitos (re)significados sobre itens utilizados nos kits de RPL (a exemplo do que é um LED) ou termos diretamente ligados ao computador como "desktop", "file", "barra de tarefa" etc.

Uma das experiências apresentadas em sua dissertação na perspectiva da "(Re)construção de Conceitos Científico-tecnológicos" responde ao $\mathrm{Cl} 4$ e trata de um educando que compreende que para acender um LED de 3,0V ele necessita de duas pilhas/baterias de potência de 1,5V. Ou seja, a partir da prática, o educando pode compreender o porquê de utilizar as pilhas com uma dada potência para fazer o circuito elétrico funcionar e acionar o LED que também possui uma potência específica.

Entre as conclusões alcançadas é evidenciado que o trabalho apresenta uma proposta de

[...] solução colaborativa e solidária, características próprias da comunidade de Software Livre. Foi observado que os educandos aprendem com o desafio de dominar os recursos da Robótica a construir seu próprio projeto, articulando diversos conteúdos [...], agregando conteúdos escolares com práticas reais/concretas (CÉSAR, 2009, p. 115).

E das diversas vantagens do trabalho com a RPL, é visto que ela

[...] estimula a exploração de aspectos ligados à pesquisa e à ciência. Além de promover a construção de conceitos disciplinares, interdisciplinares, multidisciplinares, pluridisciplinares e transdisciplinares - ligados à Física, Matemática, Geografia, História, Arquitetura, Ciências Sociais etc. -, as experiências ligadas à Robótica Pedagógica possuem um enorme potencial de desenvolvimento do espírito científico. Indiretamente, isso pode significar a formação de futuros pesquisadores (CÉSAR, 2009, p. 117).

O terceiro trabalho analisado, Scholar_03, foi escrito por De Souza e César. Tratase de um artigo intitulado "A educação de surdos e a robótica pedagógica livre". Nesse artigo são defendidos os fundamentos da RPL em Espaços Multirreferenciais de Aprendizagem, com destaque à educação de Surdos.

Os autores abordam questões relacionadas à inclusão social, evidenciando o respeito e a busca pelo reconhecimento das potencialidades e limitações das pessoas que requerem uma atenção especial, e assim poder mudar o pensamento generalizado de que "o sujeito com necessidade educacional especial ainda é visto como um indivíduo incapaz, doente, e, muitas vezes, indesejado nos círculos sociais" (DE SOUZA; CÉSAR, 


\section{4, p. 137).}

Um outro ponto discutido nesse artigo se refere à baixa oferta de profissionais com Certificação de Proficiência na Língua Brasileira de Sinais em relação à demanda do mercado, abrindo espaço para a ação de intérpretes não-qualificados que acabam tendo uma influência não satisfatória no processo educacional de estudantes surdos, comprometendo sua continuidade na vida acadêmica. Grande destaque é dado às dificuldades no processo de aprendizagem da Língua Portuguesa, não apenas pelos estudantes surdos como também pelos ouvintes.

Para De Souza e César (2014), o aprendizado de LIBRAS e da Língua Portuguesa, quando mediados pelo uso das TIC, passa por um redimensionamento e esses instrumentos tecnológicos oferecem uma infinidade de recursos que podem não apenas ampliar as capacidades humanas como também modificar a relação homem-máquina.

Por isso, acreditamos que as TIC podem potencializar o aprendizado dos educandos Surdos, pois, além de oferecer uma infinidade de informações, imagens, vídeos e sons (audíveis para alguns Surdos), favorece a produção e a disseminação dos conhecimentos produzidos pelos mesmos, estimulando a explicitação de suas ideias e sua criatividade (DE SOUZA; CÉSAR, 2014, p. 141).

O artigo destaca a importância do fazer e divulgar o conhecimento científico, desmistificando o pensamento de que a ciência está restrita aos cientistas e grandes centros de pesquisa e que, através dessa ação, o educando pode mudar a sua maneira de ler e se relacionar com o mundo.

As ações propostas objetivam "disseminar informações e estimular a (re)construção de conhecimentos através dos fundamentos da Robótica Pedagógica Livre" (DE SOUZA; CÉSAR, 2014, p. 143), através da produção de kits de Robótica Pedagógica Livre, com a utilização de materiais de baixo custo e sucatas eletrônicas, utilizando a filosofia do software e hardwares livres, para a construção de artefatos cognitivos e, assim, compreensão e difusão de conceitos científicos e tecnológicos.

\subsection{Resultado e discussão}

Algumas observações dizem respeito à pouca quantidade de trabalhos que abordam de forma não superficial os assuntos relacionados à $C \& T$, na perspectiva do Letramento Científico através da metodologia da Robótica Pedagógica - seja ela Livre ou Proprietária - com enfoque na democratização do conhecimento científico-tecnológico.

A pesquisa foi inicialmente realizada com uma string que abrangia uma busca mais ampla e levava em consideração todos os termos da pesquisa. Ela foi realizada na Biblioteca Digital Brasileira de Teses e Dissertações, utilizando a string (Construção de Conceitos CientíficoTecnológicos)AND((alfabetização)OR(Letramento)OR(Robótica)OR(Democratização do Conhecimento)) e sem delimitar o recorte temporal. Foram retornados 120 textos que não passaram pelos critérios definidos no protocolo do mapeamento, principalmente por nenhum texto envolver trabalhos relacionados à RP.

As obras analisadas apresentam trabalhos realizados com Robótica Pedagógica 
Livre em Espaços Multirreferenciais de Aprendizagem como uma proposta emancipatória sociodigital, cultural e inclusiva. Através dela, a democratização do conhecimento, a (re)construção e (re)significação dos conceitos científicos-tecnológicos podem ser trabalhados na construção de artefatos cognitivos seguindo as diretrizes do software e hardware livres na estimulação à exploração de aspectos ligados à democratização do conhecimento científico.

Esse mapeamento sistemático foi de grande utilidade para o desenvolvimento da pesquisa abordada neste artigo, pois serviu como panorama para identificar as produções desenvolvidas sobre como os assuntos de C\&T são trabalhados no ambiente escolar através do uso da robótica pedagógica e se essas produções visam a propostas de trabalho relacionadas à alfabetização científica ou letramento científico através da RP, assim como identificar as propostas e/ou métodos adotados para trabalhar assuntos de ciência e tecnologia.

\section{Conclusão}

$\mathrm{Na}$ pesquisa aqui apresentada, pode-se constatar que a literatura é escassa em relação à apresentação de iniciativas que façam uso da metodologia da Robótica Pedagógica (seja ela livre ou proprietária), a fim de democratizar o conhecimento científico. Entre os trabalhos encontrados e relevantes à análise, ganha destaque o professor Danilo César em suas práticas que visam não só à democratização do conhecimento científico, como também à inclusão e emancipação sociodigital através dos trabalhos que contemplam a utilização da Robótica Pedagógica Livre.

Acreditamos que a quantidade de trabalhos encontrados através dos mecanismos de buscas utilizados no mapeamento feito esteja relacionada aos diferentes propósitos de pesquisa, forma como os pesquisadores categorizam os seus trabalhos e determinam suas palavras-chave. A Robótica Pedagógica tem sido objeto de trabalho e estudo há algumas décadas e tem-se visto isso aqui no Brasil, através do crescimento de mostras científicas e olimpíadas, porém o foco dessas produções nem sempre se relacionam ao desenvolvimento de estratégias de democratização do conhecimento científico.

Esperamos que, não obstante, mais trabalhos realizados por pesquisadores brasileiros com a mesma temática abordada no mapeamento sistemático da literatura apresentado neste artigo sejam desenvolvidos e publicados nos veículos de divulgação científica.

\section{Referências}

CÉSAR, D. R. Potencialidades e limites da robótica pedagógica livre no processo de (re)construção de conceitos científico-tecnológicos a partir do desenvolvimento de artefatos robóticos. 2009. 135 f. Dissertação (Mestrado em Educação) - Curso de Programa de Pós-graduação em Educação, Universidade Federal da Bahia, Salvador, 2009.

CÉSAR, D. R. Robótica pedagógica livre: uma alternativa metodológica para a 
emancipação sociodigital e a democratização do conhecimento. 2013. 220 f. Tese (Doutorado em Difusão do Conhecimento) - Curso de Faculdade de Educação, Universidade Federal da Bahia, Salvador, 2013.

CHASSOT, A. Alfabetização científica: questões e desafios para a educação. ljuí: Editora UNIJUÍ, 2000.

CHASSOT, A. Alfabetização científica: uma possibilidade para a inclusão social. Revista Brasileira de Educação, Rio de Janeiro, nº. 22, p. 89-100, jan-abr. 2003.

CULKIN, J. Introduction to Arduino. Introduction to Arduino. 5 set. 2011. Disponível em: <http://www.jodyculkin.com/comics-2/introduction-to-arduino>. Acesso em: 03 mar. 2017.

FERREIRO, E.; TEBEROSKY, A. Psicogenese da língua escrita. Tradução de Diana Myriam Lichtenstein, Liana di Marco, Nestor Jerusalinsky. 4. ed. Porto Alegre: Artes Médicas, 1991.

FREIRE, P. Papel da educação na humanização. Tradução de Carlos Souza. In: JAGUARIBE, H. Desenvolvimento econômico e desenvolvimento político. São Paulo: Ed. Paz e Terra, 1969. p. 123-132. Disponível em: < http://www.acervo.paulofreire.org:8080/jspui/bitstream/7891/1127/1/FPF_OPF_01_0003.p df>. Acesso em: 19 jun. 2017.

FREIRE, P.; MACEDO, D. Alfabetização: leitura do mundo, leitura da palavra. São Paulo: Paz e Terra, 1990.

GOMES, P. M. R. A vulgarização de um vocabulário científico. TRADTERM, São Paulo, v. 2, p. 85-91, 1995.

INEP. OECD. PISA 2015 - Programa Internacional de Avaliação de Estudantes. Matriz de avaliação de ciências. Disponível em: $<$ http://download.inep.gov.br/acoes_internacionais/pisa/marcos_referenciais/2015/matriz de_ciencias_PISA_2015.pdf $>$. Acesso em: 12 mar. 2017.

KITCHENHAM, B. Procedures for Performing Systematic Reviews. Joint Technical Report (Software Engineering Group) - Keele University, [S.I.], 2004. 33 f. Disponível em: $<$ http://www.inf.ufsc.br/ aldo.vw/kitchenham.pdf>. Acesso em: 18 jan. 2018.

KRASILCHIK, M; MARANDINO, M. Ensino de Ciências e cidadania. São Paulo: Moderna, 2004.

OLIVEIRA, H. C. de; DA SILVA HOUNSELL, M.; KEMCZINSKI, A. Mapeamento sistemático de metodologias de desenvolvimento centrado no usuário para jogos sérios. In: BRAZILIAN SYMPOSIUM ON COMPUTERS IN EDUCATION (SIMPÓSIO BRASILEIRO DE INFORMÁTICA NA EDUCAÇÃO-SBIE), 25, Mato Grosso do Sul, 2014, Anais do XXV Simpósio Brasileiro de Informática na Educação, Porto Alegre, 2014. p. 727-736. 
PAULA, H. F.; LIMA, M. E. C. C. Educação em ciências, letramento e cidadania. Química Nova na Escola, São Paulo, v. 26, n. 1, p. 3-9, 2007.

PEREIRA, J. C.; TEIXEIRA, M. do R. F. Alfabetização científica, letramento científico e o impacto das políticas públicas no ensino de ciências nos anos iniciais: uma abordagem a partir do PNAIC. X ENCONTRO NACIONAL DE PESQUISA EM EDUCAÇÃO EM CIÊNCIAS - X ENPEC, Águas de Lindóia, 2015. Anais... Águas de Lindóia, 2015. Disponível em: <http://www.xenpec.com.br/anais2015/resumos/R1313-1.PDF>. Acesso em: 08 mar. 2017.

RUI, H. M. G. Ciência, técnica e tecnologia e suas implicações na sociedade moderna. Revista FACEVV, Vila Velha, $\mathrm{n}^{\circ}$. 8, jan-jun. 2012.

SABBATINI, M. Museos y Centros de Ciência Virtuales. Complementación y Potenciación del Aprendizaje de ciências a través de Experimentos Virtuales. 2004. 575f. Tese de Doutorado. Instituto Universitario de Ciencia de la Educación. Universidad de Salamanca, 2004.

SILVA, Í. D. et al. Mapeamento sistemático. Almanaque para popularização de ciência da computação. Metodologia científica e tecnológica. Série 6, v. 10, parte 4, 2018.

SOARES, M. Letramento: um tema em três gêneros. Belo Horizonte: Autêntica, 1998.

DE SOUZA, R. S.; CESAR, D. R. A educação de surdos e a robótica pedagógica livre. Texto livre: linguagem e tecnologia, v. 7, n. 2, p. 136-147, 2014. Disponível em: <http://www.periodicos.letras.ufmg.br/index.php/textolivre/article/view/6396>. Acesso em: 14 dez. 2018.

TEIXEIRA, J. N. Categorização do nível de letramento científico dos alunos de Ensino Médio. São Paulo: Universidade de São Paulo, 2007.

Recebido em dia 04 de outubro de 2018. Aprovado em dia 05 de novembro de 2018. 